\title{
Allergy promotes alopecia areata in a subset of patients
}

\author{
Xingqi Zhang ${ }^{1}$, Kevin J. McElwee ${ }^{2,3}$ \\ https://doi.org/10.1111/exd.14027
}

${ }^{1}$ Department of Dermatology, The First Affiliated Hospital, Sun Yat-sen University, Guangzhou, Guangdong, People's Republic of China.

${ }^{2}$ Centre for Skin Sciences, University of Bradford, Bradford, United Kingdom.

${ }^{3}$ Department of Dermatology and Skin Science, University of British Columbia, Vancouver, Canada.

Correspondence: Xingqi Zhang, M.D., Ph.D.

Department of Dermatology, The First Affiliated Hospital, Sun Yat-sen University, 58 Zhongshan Road II, Guangzhou, Guangdong 510080, People’s Republic of China.

Conflicts of Interest: Kevin McElwee is Chief Scientific Officer for Replicel Life Sciences Inc. All other authors state no conflict of interest.

Author Contribution: $\mathrm{XZ}$ proposed the topic, reviewed the literature and wrote the article. KM reviewed the article, added personal expertise, and edited the article.

Key Words: Alopecia areata, atopy, allergy, dust mites. 


\section{Abstract:}

In this commentary, we focus on allergy as a facilitating factor in the pathogenesis of alopecia areata (AA). From previous studies on AA, it is well known that subsets of patients can have one or more of; seasonal relapse, comorbid atopic rhinitis, asthma and dermatitis, lesional infiltrating eosinophils and plasma cells, high levels of total $\operatorname{IgE}$, specific IgE for house dust mites (HDM), and/or disrupted skin barrier function by the evaluation of filaggrin. Allergy and AA share a similar genetic background; both contributing to an immune reaction imbalance. Furthermore, adjunctive treatment with antihistamines, or desensitization for HDM, can reduce the severity of alopecia in atopic AA patients. Therefore, allergies may contribute to the onset and relapse of AA. Identification of an allergic or atopic immune component in AA patient subsets may indicate adjunctive treatment intervention measures against allergies should be taken which may improve the success of conventional AA treatment. 


\section{Background}

Several factors are suspected as alopecia areata (AA) disease onset triggers or modulators including viruses, stress, and diet. ${ }^{[1-5]}$ The complexity of AA pathogenesis and the wide variation in clinical presentations lead us to suggest that multiple pathogenetic factors must come together in (un)desirable combinations to induce autoimmunity against hair follicle specific antigens. ${ }^{[6,7]}$ As the AA immune response is activated systemically, inflammatory cells infiltrate and accumulate in the skin and progressively focus on hair follicles. ${ }^{[8,9]}$ If and when a local threshold level of immune activity is achieved, ${ }^{[10]}$ follicular regression is induced in local areas of the scalp. ${ }^{[11]}$

\section{Hypothesis}

For subsets of patients, allergy may contribute to systemic activation of autoimmune mechanisms. Allergy may also contribute to the local immune response against affected hair follicles.

\section{Premise}

Several items of evidence may link allergy with AA:

1. Seasonal relapse and recovery in AA. Reports suggest first AA onset occurs more 
often in spring and summer; ${ }^{[12]}$ even in horses. ${ }^{[13]}$ Case studies suggest some patients exhibit regular seasonal cycling of AA. ${ }^{[14]}$ These reports could reflect seasonal changes in allergen exposure, and/or viral load.

2. Comorbid atopic diseases; rhinitis, asthma, dermatitis and food allergy. Atopy increases the risk of developing AA. ${ }^{[15,16]}$ Early-onset AA, or alopecia totalis (AT) and alopecia universalis (AU), have an increased prevalence concurrent with atopy. ${ }^{[14,17-20]}$ Presence of atopy is a poor prognostic factor for AA. ${ }^{[17]}$ Spontaneous chronic urticaria has also been linked to AA. ${ }^{[19,21]}$

3. Mutation of the filaggrin gene related to $A A$. A filaggrin gene mutation is associated with atopic dermatitis and a severe clinical AA subtype. ${ }^{[22,23]}$

4. Genetic relationships between allergies and AA. GWAS studies show linkage of AA to gene pathways also active in atopic/allergic conditions. ${ }^{[24]}$

5. Elevated serum IgE and AA. High titers of serum IgE have been found in several AA studies, even in supposedly non-atopic patients. ${ }^{[25-29]}$ In our own studies, high IgE titers correlate to relative resistance to treatment of AA. ${ }^{[30]}$

6. Eosinophil infiltration in AA lesions. Eosinophils are variably present in AA scalp lesions. ${ }^{[8,28,31,32]}$ Previously, we also found plasma cells in the infiltrating cell 
population. ${ }^{[8]}$ Presence of eosinophils may be a favorable prognosis indication for AA disease duration. ${ }^{[8]}$

7. Increased mast cell number and activity in AA. Elevated mast cell numbers are present in AA lesions; urticaria may first appear in bald areas of the scalp which contain large numbers of mast cells. ${ }^{[33-35]}$

8. Allergy to dust mites is associated with AA severity. AA patients might have a predisposing background which increases the risk of $\mathrm{T}$ cell-driven skin disease development. $^{[36]}$ Focusing on house dust mite (HDM) allergy, one of the most common allergies in South China, our study suggested allergy to HDM correlates to AA severity and early-onset. ${ }^{[8]}$

9. Desensitization to dust mites can decrease AA severity. In a study conducted by our group, AA patients with HDM allergy that received desensitization immunotherapy alongside standard treatments for AA (corticosteroids or contact sensitization with diphenylcyclopropenone), exhibited a reduced extent of alopecia by 3 years as compared to AA patients with HDM allergy receiving standard treatments alone. ${ }^{[30]}$ The study suggests allergy to HDM may help establish local inflammation in a subset of atopic AA patients.

10. Steroid treatment dose for $A A$ is similar to that for allergic diseases. In AA, the 
systemic steroid dosage needed to improve hair growth is relatively low; 0.3$0.5 \mathrm{mg} / \mathrm{kg} / \mathrm{day},{ }^{[37]}$ similar to doses used for allergic rhinitis, but far less than that needed in typical autoimmune diseases, such as systemic lupus erythematosus. ${ }^{[38,39]}$

11. Both Th1 and Th2 type immune responses are present in $A A$. Immune reaction in allergy involves a Th2-dominant pattern, often represented by overexpression of IL-4 and IL-5. In contrast, AA is considered a T cell driven, Th1-dominant lesion, primarily represented by IFN $\gamma .{ }^{[40,41]}$ However, both Th1 and Th2 cytokines are significantly elevated in AA patients. ${ }^{[42,43]}$ In AA mice both Th1 and Th2 cytokines are increased very early in the disease pathogenesis, even in advance of overt hair loss. ${ }^{[44]}$ Th2-type cytokines may be associated with the persistence of AA and/or may make patients more resistant to successful therapy. ${ }^{[35]}$

12. Anti-histamines have been successfully used to treat AA. In several reports anti-histamine drugs have been shown beneficial for some AA patients. ${ }^{[45-50]}$ Some Japanese colleagues confirm they currently use anti-histamines as an adjunctive treatment alongside corticosteroids.

Considering the evidence above, allergy may be a constitutional factor in the pathogenic process, influencing onset, perpetuation, and relapse of AA.

\section{How to test the hypothesis}


Testing the hypothesis may not be straight forward. If allergens trigger AA onset, allergen responses need not persist after the trigger event. As with many autoimmune diseases, the AA disease mechanism can be self-perpetuating once activated. ${ }^{[51]}$ However, if allergen immune responses persist in the AA disease mechanism it should be possible to define the significance and whether targeting allergic immune responses would help with treating AA. Using mouse models of AA, it may be possible to determine whether allergens induce or exacerbate the disease intensity, extent, speed of development, or resistance to treatment. ${ }^{[52,53]}$

With humans, adjunctive treatments against allergies could be used to observe whether there is an improved effect on AA resolution. From our observations, ${ }^{[30,43]}$ HDM desensitization might modulate the balance of Th1/Th2 cytokine activity in AA. Allergen desensitization or antihistamine use in atopic AA patients may not directly treat AA, but may change immune activity so as to enable hair growth in response to standard treatments.

\section{Relevance and perspectives}

Allergy may serve as a facilitating factor in AA pathogenesis, with regards to onset, relapse, and severity, in a subset of patients. This is not a new observation, ${ }^{[54]}$ but it seems to have been largely disregarded. As our understanding of AA pathobiology 
improves, allergy and/or atopic disease mechanisms may be recognized as playing a greater role in AA development and the collapse of hair follicle immune privilege; more research is needed to unveil this complicated issue. ${ }^{[55]}$

In confirming a linkage between allergy and AA, adjunctive intervention measures can be taken to improve treatment success for AA patients with atopy (Figure 1). We believe that testing for common allergens and desensitizing allergic patients should become a routine procedure in AA clinics. 


\section{References}

[1] C. T. Richardson, M. S. Hayden, E. S. Gilmore, B. Poligone. Am J Clin Dermatol. 2018, 19, 119.

[2] C. H. Chu, Y. P. Cheng, J. Y. Chan. Pediatr Dermatol. 2016, 33, e218.

[3] R. P. Wise, K. P. Kiminyo, M. E. Salive. JAMA. 1997, 278, 1176.

[4] K. J. McElwee, S. Niiyama, P. Freyschmidt-Paul, E. Wenzel, S. Kissling, J. P. Sundberg, R. Hoffmann. Exp Dermatol. 2003, 12, 30.

[5] K. J. McElwee, K. Silva, W. G. Beamer, L. E. King, Jr., J. P. Sundberg. Exp Dermatol. 2001, 10, 420 .

[6] H. Guo, Y. Cheng, J. Shapiro, K. McElwee. Expert Rev Clin Immunol. 2015, 11, 1335.

[7] K. McElwee, P. Freyschmidt-Paul, A. Ziegler, R. Happle, R. Hoffmann. Eur J Dermatol. 2001, 11,11 .

[8] B. Zhang, Y. Zhao, Z. Cai, S. Caulloo, K. J. McElwee, Y. Li, X. Chen, M. Yu, J. Yang, W. Chen, X. Tang, X. Zhang. Australas J Dermatol. 2013, 54, 184.

[9] K. J. McElwee, K. Silva, D. Boggess, L. Bechtold, L. E. King, Jr., J. P. Sundberg. Vet Pathol. 2003, 40, 643 .

[10] H. Kang, W. Y. Wu, B. K. Lo, M. Yu, G. Leung, J. Shapiro, K. J. McElwee. J Invest Dermatol. 2010, 130, 2677.

[11] W. Lu, J. Shapiro, M. Yu, A. Barekatain, B. Lo, A. Finner, K. McElwee. Expert Rev Mol Med. 2006, 8,1 .

[12] D. L. Crosby, W. R. Gammon. J Am Acad Dermatol. 1989, 21, 806.

[13] D. E. Hoolahan, S. D. White, C. A. Outerbridge, P. L. Shearer, V. K. Affolter. Vet Dermatol. 2013, 24, 282.

[14] C. Goh, M. Finkel, P. J. Christos, A. A. Sinha. J Eur Acad Dermatol Venereol. 2006, 20, 1055.

[15] N. Barahmani, M. B. Schabath, M. Duvic, R. National Alopecia Areata. J Am Acad Dermatol. 2009, 61, 581 .

[16] A. M. Drucker, J. M. Thompson, W. Q. Li, E. Cho, T. Li, E. Guttman-Yassky, A. A. Qureshi. Allergy. 2017, 72, 831.

[17] F. B. De Waard-van der Spek, A. P. Oranje, D. M. De Raeymaecker, J. D. Peereboom-Wynia. Clin Exp Dermatol. 1989, 14, 429.

[18] E. A. Thomas, R. S. Kadyan. Indian J Dermatol. 2008, 53, 70.

[19] G. C. Mohan, J. I. Silverberg. JAMA Dermatol. 2015, 151, 522.

[20] N. Garzorz, M. Alsisi, A. Todorova, A. Atenhan, J. Thomas, F. Lauffer, J. Ring, C. Schmidt-Weber, T. Biedermann, S. Eyerich, K. Eyerich. J Eur Acad Dermatol Venereol. 2015, 29, 2429.

[21] E. Magen, T. Chikovani, D. A. Waitman, N. R. Kahan. Allergy Asthma Proc. 2018, 39, 96.

[22] R. C. Betz, J. Pforr, A. Flaquer, S. Redler, S. Hanneken, S. Eigelshoven, A. K. Kortum, T. Tuting, J. Lambert, J. De Weert, A. M. Hillmer, C. Schmael, T. F. Wienker, R. Kruse, G. Lutz, B. Blaumeiser, M. M. Nothen. J Invest Dermatol. 2007, 127, 2539.

[23] S. Ono, A. Otsuka, Y. Miyachi, K. Kabashima. Eur J Dermatol. 2012, 22, 785.

[24] L. Petukhova, A. M. Christiano. J Invest Dermatol. 2016, 136, 314. 
[25] E. Kasumagic-Halilovic, A. Prohic. Acta Dermatovenerol Croat. 2006, 14, 149.

[26] E. A. Attia, D. El Shennawy, A. Sefin. Dermatol Res Pract. 2010, 2010, 503587.

[27] Y. Zhao, B. Zhang, S. Caulloo, X. Chen, Y. Li, X. Zhang. Indian J Dermatol Venereol Leprol. 2012, 78, 709 .

[28] O. A. Bakry, R. M. El Shazly, M. A. Basha, H. Mostafa. Indian Dermatol Online J. 2014, 5, 122.

[29] T. Yoshimasu, M. Uede, N. Kanazawa, N. Mikita, Y. Yamamoto, T. Ito, F. Furukawa. Eur J Dermatol. 2014, 24, 500.

[30] Z. Zeng, S. Li, Y. Ling, Y. Ye, X. Zi, J. Yang, K. McElwee, X. Zhang. Exp Dermatol. 2019.

[31] S. Ono, A. Otsuka, Y. Miyachi, K. Kabashima. Acta Derm Venereol. 2013, 93, 185.

[32] O. Ibrahim, W. F. Bergfeld, M. Piliang. J Investig Dermatol Symp Proc. 2015, 17, 58.

[33] L. Juhlin. Arch Dermatol. 1963, 88, 771.

[34] M. Bertolini, F. Zilio, A. Rossi, P. Kleditzsch, V. E. Emelianov, A. Gilhar, A. Keren, K. C. Meyer, E. Wang, W. Funk, K. McElwee, R. Paus. PLoS One. 2014, 9, e94260.

[35] X. Zhang, Y. Zhao, Y. Ye, S. Li, S. Qi, Y. Yang, H. Cao, J. Yang, X. Zhang. Arch Dermatol Res. 2015, 307, 319 .

[36] S. F. Li, X. T. Zhang, S. L. Qi, Y. T. Ye, H. Cao, Y. Q. Yang, K. J. McElwee, X. Zhang. Clin Exp Dermatol. 2015, 40, 171.

[37] L. C. Strazzulla, E. H. C. Wang, L. Avila, K. Lo Sicco, N. Brinster, A. M. Christiano, J. Shapiro. J Am Acad Dermatol. 2018, 78, 15.

[38] A. D. Steinberg, S. C. Steinberg. Arthritis Rheum. 1991, 34, 945.

[39] D. Apostolopoulos, E. F. Morand. Rheumatology (Oxford). 2017, 56, i114.

[40] C. N. Giordano, A. A. Sinha. Eur J Dermatol. 2013, 23, 308.

[41] P. Freyschmidt-Paul, K. J. McElwee, R. Hoffmann, J. P. Sundberg, M. Vitacolonna, S. Kissling, M. Zoller. Br J Dermatol. 2006, 155, 515.

[42] T. Ito, Y. Tokura. Exp Dermatol. 2014, 23, 787.

[43] Y. Gong, Y. Zhao, X. Zhang, S. Qi, S. Li, Y. Ye, J. Yang, S. Caulloo, K. J. McElwee, X. Zhang. Exp Dermatol. 2018, In press.

[44] M. Zoller, K. J. McElwee, P. Engel, R. Hoffmann. J Invest Dermatol. 2002, 118, 983.

[45] S. Inui, T. Nakajima, N. Toda, S. Itami. J Dermatol. 2009, 36, 323.

[46] S. Inui, T. Nakajima, S. Itami. J Dermatol. 2007, 34, 852.

[47] T. Ito, T. Fujiyama, H. Hashizume, Y. Tokura. J Dermatol Sci. 2013, 72, 68.

[48] M. Ohyama, A. Shimizu, K. Tanaka, M. Amagai. J Dermatol Sci. 2010, 58, 154.

[49] G. Landi, A. F. Finzi. Minerva Dermatol. 1964, 39, 102.

[50] H. Ogawa, R. Imai, S. Nishiyama, H. Nakajima, Z. Ikezawa, Y. Tokuda, I. Takiuchi. Skin research. 1994, 36, 60 .

[51] E. Darwin, P. A. Hirt, R. Fertig, B. Doliner, G. Delcanto, J. J. Jimenez. Int J Trichology. 2018, $10,51$.

[52] K. J. McElwee, M. Yu, S. W. Park, E. K. Ross, A. Finner, J. Shapiro. Dermatology. 2005, 211, 47.

[53] J. P. Sundberg, K. McElwee, M. A. Brehm, L. Su, L. E. King, Jr. J Investig Dermatol Symp Proc. 2015, 17, 23.

[54] T. Ikeda. Dermatologica. 1965, 131, 421.

[55] R. Paus, S. Bulfone-Paus, M. Bertolini. J Investig Dermatol Symp Proc. 2018, 19, S12. 


\section{Figure 1}

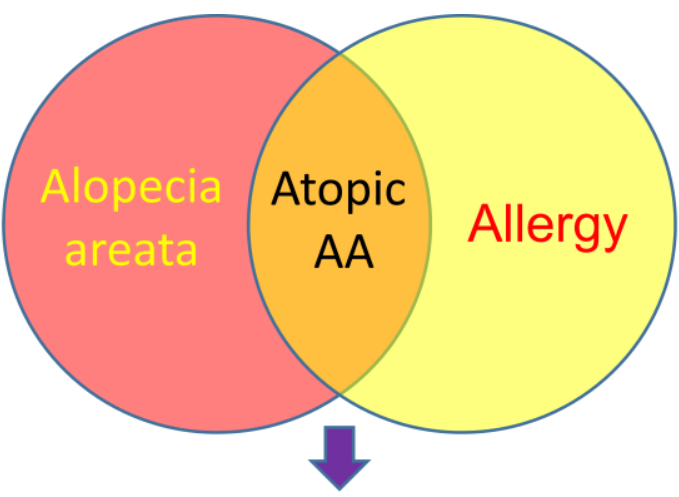

Atopic AA patients:

High IgE levels

Elevated IL-4 levels

Increased mast cell and eosinophil cell numbers in AA lesions

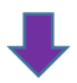

Increased risk of:

Early onset

More extensive AA

Multiple relapses

Resistance to standard AA treatments

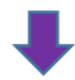

AA treatment:

Corticosteroids

Contact sensitizing agents Jak/Stat inhibitors?
Atopy treatment:

Antihistamines

Allergen desensitization IL-4 inhibitors?

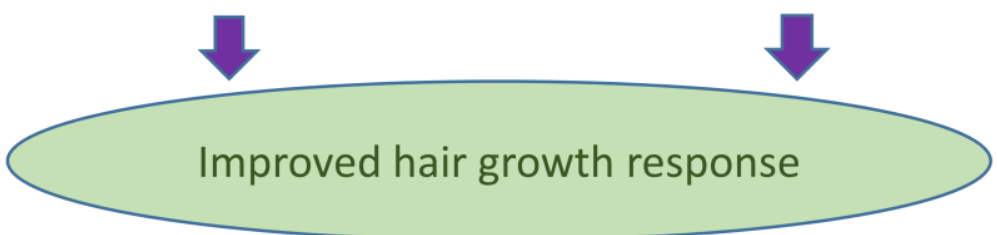

Figure 1. Summary of atopy in alopecia areata 